\title{
Synthesis, XRD, TEM, EPR, and Optical Absorption Spectral Studies of $\mathrm{CuZnO}_{2}$ Nanocompound
}

\author{
T. Ravindra Reddy, ${ }^{1}$ K. Thyagarajan, ${ }^{2}$ S. Lakshmi Reddy, ${ }^{1}$ and Tamio Endo ${ }^{3}$ \\ ${ }^{1}$ Department of Physics, S.V.D. College, Kadapa 516 003, India \\ ${ }^{2}$ Department of Physics, Jawaharlal Nehru Technological University College of Engineering, YSR District, Pulivendula, \\ Andhra Pradesh 516 390, India \\ ${ }^{3}$ Faculty of Engineering, Mie University, Tsu, Mie 514-8507, Japan
}

Correspondence should be addressed to S. Lakshmi Reddy; drslreddy_in@yahoo.com

Received 5 February 2014; Revised 18 March 2014; Accepted 20 March 2014; Published 11 May 2014

Academic Editor: Bobby G. Sumpter

Copyright (C) 2014 T. Ravindra Reddy et al. This is an open access article distributed under the Creative Commons Attribution License, which permits unrestricted use, distribution, and reproduction in any medium, provided the original work is properly cited.

Synthesis of nano $\mathrm{CuZnO}_{2}$ compound is carried out by thermal decomposition method. The crystalline phase of the material is characterized by XRD. The calculated unit cell constants are $a=3.1 \AA$ and $c=3.4786 \AA$ and are of tetragonal structure. The unit cell constants are different from wurtzite (hexagonal) which indicate that a nanocompound is formed. Further TEM images reveal that the metal ion is in tetragonal structure with oxygen ligands. The prepared $\mathrm{CuZnO}_{2}$ is then characterized for crystallite size analysis by employing transmission electron microscopy (TEM). The size is found to be $100 \mathrm{~nm}$. Uniform bright rings are noticed in the TEM picture suggesting that the nanocrystals have preferential instead of random orientations. The selectedarea electron diffraction (SAED) pattern clearly indicates the formation of $\mathrm{CuO}-\mathrm{ZnO}$ nanocompound. The nature of bonding is studied by electron paramagnetic resonance (EPR). The covalency character is about 0.74 and thus the compound is electrically less conductive. Optical absorption spectral studies suggest that $\mathrm{Cu}(\mathrm{II})$ is placed in tetragonal elongation crystal field. The spin-orbit coupling constant, $\lambda$, is calculated using the EPR and optical absorption spectral results suggest some covalent bond between metal and ligand. Near infrared (NIR) spectra are due to hydroxyl and water fundamentals.

\section{Introduction}

Semiconducting compounds have drawn much attention during the last few years because of their unique properties and immense potential applications. In recent years, zincoxide $(\mathrm{ZnO})$ has also been studied for its use as a promising material for UV light emitting diodes and diode lasers because of its wide band gap energy $3.4 \mathrm{eV}$ and high binding energy $(\sim 60 \mathrm{meV})$. $\mathrm{ZnO}$ has a stable wurtzite structure (hexagonal) with lattice constants $a=3.25 \AA$ and $c=$ $5.25 \AA$ and is composed of a number of alternating planes of tetrahedrally coordinated $\mathrm{O}^{2-}$ and $\mathrm{Zn}^{2+}$ ions stacked alternately along the $\mathrm{C}$-axis [1]. Zinc-oxide is an n-type semiconductor. When transition metal elements are doped, the compound exhibits ferromagnetism at room temperature. This type of doping is helpful in adjusting the energy level states of $\mathrm{ZnO}$ and hence its properties change [2]. Due to structural stability and other parameters transition metal doped zinc-oxides are used in gas sensors.

The ionic radius of $\mathrm{Cu}(\mathrm{II})$ is $0.73 \AA$ and that of $\mathrm{Zn}(\mathrm{II})$ is $0.84 \AA$ and the charges are the same. Therefore $\mathrm{Cu}$ and $\mathrm{Zn}$ are mutually replaceable and are surrounded by oxygen molecules in the oxide form, since $\mathrm{Cu}^{2+}$, being a $\mathrm{d}^{9}$ system, is prone to Jahn-Teller distortion. Hence a EPR study of these ions will provide information about the type of distortion and nature of bonding between metal and ligand. In the present investigation, XRD, TEM, optical absorption, and NIR and EPR techniques are used to know the crystalline phase and site symmetry of $\mathrm{Cu}^{2+}$ in the material.

\section{Synthesis of Nano $\mathrm{CuZnO}_{2}$}

$9.98 \mathrm{~g}$ of cupric acetate $(0.05$ moles $)$ and $10.97 \mathrm{~g}$ of zinc acetate $(0.05$ moles $)$ are dissolved separately in $100 \mathrm{~mL}$ of 
demineralized water. The solutions are then transferred into a conical flask and $1 \mathrm{~mL}$ of glacial acetic acid is added to the mixture. The mixture solution is transferred to a reflux flask which is then kept in a CATA $2 \mathrm{R}$ microwave reactor (MWR) and heated to boiling. The heating is continued for five minutes with constant stirring. The color of the solution changes from blue to greenish brown. Then $0.8 \mathrm{gm}$ of $\mathrm{NaOH}$ is added and heating and stirring are continued in MWR for about 5 minutes. The color of the solution changes from greenish brown to brownish black. The solution is allowed to cool at room temperature and then filtered by suction and washed with deionised water and ethanol. The precipitate is dried in open air for about 3 days:

$$
\begin{aligned}
& \mathrm{Cu}\left(\mathrm{CH}_{3} \mathrm{COO}\right)_{2}+\mathrm{Zn}\left(\mathrm{CH}_{3} \mathrm{COO}\right)_{2}+4 \mathrm{NaOH} \\
& \underset{\text { MWR at } 100{ }^{\circ} \mathrm{C}}{\longrightarrow} \mathrm{CuZnO}_{2}+4 \mathrm{CH}_{3} \mathrm{COONa}+2 \mathrm{H}_{2}
\end{aligned}
$$

$\mathrm{X}$-ray powder diffraction pattern of $\mathrm{CuZnO}_{2}$ compound is recorded using Philips $\mathrm{X}$-ray diffractometer operated in reflection geometry at $30 \mathrm{~mA}, 40 \mathrm{kV}$ with $\mathrm{Cu}-\mathrm{K}_{\alpha}(\lambda=$ $1.54060 \AA$ ) source at $25^{\circ} \mathrm{C}$ in the range of $10^{\circ}-75^{\circ}$. Data are collected using a continuous scan rate of one degree per 2 minutes, which are then refined into $2^{\circ}$ theta steps of $0.02^{\circ}$. The TEM images are obtained on a transmission electron microscope, Philips CM 200, operating at $200 \mathrm{keV}$ having a $0.23 \mathrm{~nm}$ resolution. EPR spectra of the powdered sample are recorded at room (RT) on JEOL JES-TE100 ESR spectrometer operating at X-band frequencies $(v=9.4 \mathrm{GHz}$ modulation $0.5 \mathrm{mT}$, with $10 \mathrm{~mW}$ power), having a $100 \mathrm{KHz}$ field modulation to obtain the first derivative EPR spectrum. DPPH with a $g$ value of 2.0036 is used for $g$ factor calculations. The optical absorption spectrum of the compound is recorded at RT on a Carey 5E UV Vis-NIR spectrophotometer in mull form in the range of 200-2000 $\mathrm{nm}$. Band component analysis is undertaken using the Jandel "PEAKFIT" software package which enabled the type of fitting function to be selected and specific parameters to be fixed or varied accordingly. Band fitting is carried out using a Lorentz-Gauss cross product function with a minimum number of component bands used for the fitting process. The Lorentz-Gauss ratio is maintained at values greater than 0.7 and fitting is undertaken until reproducible results are obtained with squared correlations of $r^{2}$ greater than 0.995 .

\section{Theory}

$\mathrm{Cu}$ (II) has an electronic configuration [Ar] $3 \mathrm{~d}^{9}$. In an octahedral crystal field, the corresponding ground state electronic configuration is $\mathrm{t}_{2 \mathrm{~g}}{ }^{6} \mathrm{e}_{\mathrm{g}}{ }^{3}$ which yields an ${ }^{2} \mathrm{E}_{\mathrm{g}}$ term. The excited electronic configuration, $\mathrm{t}_{2 \mathrm{~g}}{ }^{5} \mathrm{e}_{\mathrm{g}}{ }^{4}$, corresponds to a ${ }^{2} \mathrm{~T}_{2 \mathrm{~g}}$ term. Hence single electron transition ${ }^{2} \mathrm{E}_{\mathrm{g}} \rightarrow{ }^{2} \mathrm{~T}_{2 \mathrm{~g}}$ is expected in an octahedral crystal field. Normally, the ground ${ }^{2} \mathrm{E}_{\mathrm{g}}$ state splits due to Jahn-Teller effect and hence lowering of symmetry is expected for $\mathrm{Cu}(\mathrm{II})$ ion. This state splits into two states, that is, ${ }^{2} \mathrm{~B}_{1 \mathrm{~g}}\left(\mathrm{~d}_{x}{ }^{2}-\mathrm{d}_{y}{ }^{2}\right)$ and ${ }^{2} \mathrm{~A}_{1 \mathrm{~g}}\left(\mathrm{~d}_{z}{ }^{2}\right)$, in tetragonal symmetry and the excited term ${ }^{2} \mathrm{~T}_{2 \mathrm{~g}}$ also splits into ${ }^{2} \mathrm{~B}_{2 \mathrm{~g}}$ $\left(\mathrm{d}_{x y}\right)$ and ${ }^{2} \mathrm{E}_{\mathrm{g}}\left(\mathrm{d}_{x z}, \mathrm{~d}_{y z}\right)$ levels. In a rhombic field, ${ }^{2} \mathrm{E}_{\mathrm{g}}$ ground state splits into ${ }^{2} \mathrm{~A}_{1 \mathrm{~g}}\left(\mathrm{~d}_{x}{ }^{2}-\mathrm{d}_{y}{ }^{2}\right)$ and ${ }^{2} \mathrm{~A}_{2 \mathrm{~g}}\left(\mathrm{~d}_{z}{ }^{2}\right)$ states whereas the ${ }^{2} \mathrm{~T}_{2 \mathrm{~g}}$ splits into ${ }^{2} \mathrm{~B}_{1 \mathrm{~g}}\left(\mathrm{~d}_{x y}\right),{ }^{2} \mathrm{~B}_{2 \mathrm{~g}}\left(\mathrm{~d}_{x z}\right)$, and ${ }^{2} \mathrm{~B}_{3 \mathrm{~g}}\left(\mathrm{~d}_{y z}\right)$ states. Thus three bands are expected for tetragonal $\left(C_{4 v}\right)$ symmetry and four bands are expected for rhombic $\left(D_{2 h} / C_{2 v}\right)$ symmetry. The wave numbers of the three transitions in the tetragonal field are given by the following equations [3]:

$$
\begin{gathered}
{ }^{2} \mathrm{~B}_{1 \mathrm{~g}} \longrightarrow{ }^{2} \mathrm{~A}_{1 \mathrm{~g}}: 4 D_{s}+5 D_{t} \\
{ }^{2} \mathrm{~B}_{1 \mathrm{~g}} \longrightarrow{ }^{2} \mathrm{~B}_{2 \mathrm{~g}}: 10 D_{q} \\
{ }^{2} \mathrm{~B}_{1 \mathrm{~g}} \longrightarrow{ }^{2} \mathrm{E}_{\mathrm{g}}: 10 D_{q}+3 D_{s}-5 D_{t} .
\end{gathered}
$$

In the above formula, $D_{q}$ is the crystal field and $D_{s}$ and $D_{t}$ are tetragonal field parameters.

\section{Results and Analysis}

4.1. X-Ray Diffraction Results. Figure 1(a) shows the X-ray diffraction pattern of $\mathrm{CuZnO}_{2}$ recorded on Philips diffractometer at $25^{\circ} \mathrm{C}$. In Figure 1(a) all major peaks were indexed using Scherrer formula. The calculated unit cell constants are $a=3.1 \AA$ and $c=3.4786 \AA$, respectively. The unit cell constants are different from wurtzite (hexagonal) [1]. This behaviour of change of lattice constant is attributed to the substitutional effect of $\mathrm{Zn}^{2+}$ ions of larger ionic radius $(0.84 \AA)$ by smaller $\mathrm{Cu}^{2+}(0.73 \AA)$ ions, due to this ionic radius of lattice decreases. Hence the cell size decreases and thus shows low cell constant. Thus we expect that a nanocompound is formed. The calculated unit cell constants suggest that the nano $\mathrm{CuZnO}_{2}$ compound possesses tetragonal structure. The crystallite size of the compound is evaluated from the line broadening of the peak using DebyeScherrer equation:

$$
D_{(002)}=\frac{k \lambda}{\beta_{1 / 2} \cos \theta}
$$

(see [4]). Here $D$ is the crystallite size of the compound; $\lambda$ $(1.54060 \AA)$ is the wavelength of incident $X$ rays. $\theta$ is the corresponding Bragg angle; $\beta_{1 / 2}$ is the full width at the half maximum (FWHM) of the peak. $k$ is shape constant $(k=$ $0.9)$. The crystallite size of the nanocompound is calculated as $115 \mathrm{~nm}$.

The strain induced in powder due to crystal imperfection and distortion is calculated using

$$
\varepsilon=\frac{\beta_{h k l}}{4 \tan \theta}
$$

(see [4]). The above two equations confirmed that the peak width from crystallite size varies as $1 / \cos \theta$ and strain varies as $\tan \theta$. Assuming that the particle size and strain contributions to line broadening are independent of each other and both have a Cauchy-like profile, the observed line breadth is simply the sum of the above two equations. $\beta_{h k l}=$ $k \lambda / D \cos \theta+4 \varepsilon \tan \theta$. By rearranging we have $\beta_{h k l} \cos \theta=$ $k \lambda / D+4 \varepsilon \sin \theta$. A plot is drawn with $4 \sin \theta$ along the $X$-axis 


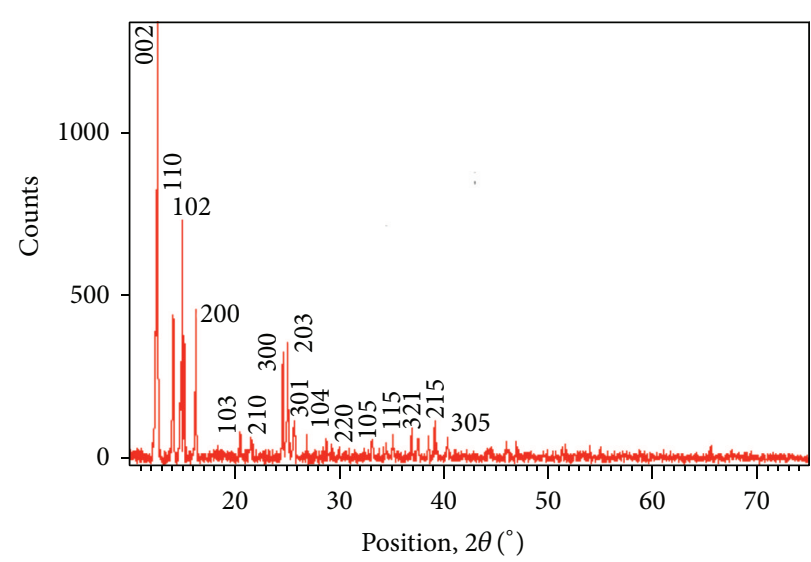

(a)

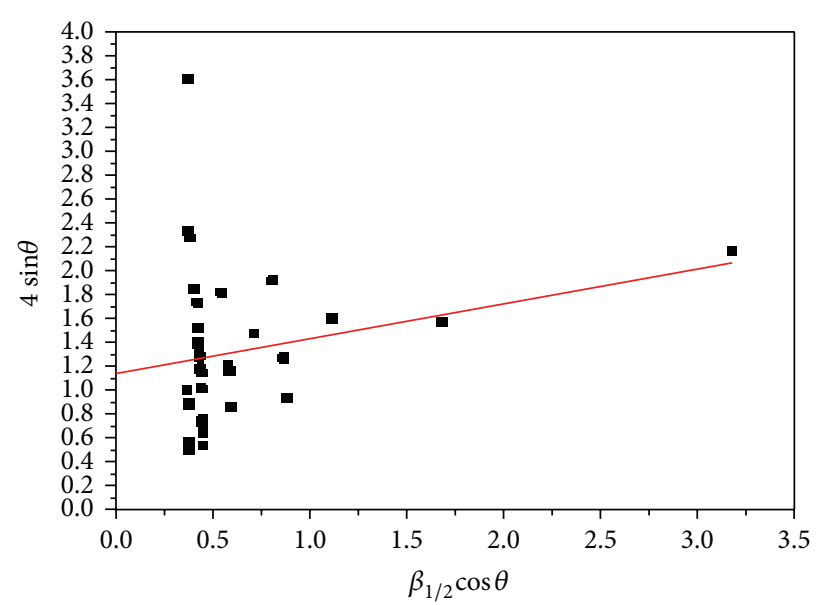

(b)

Figure 1: XRD spectrum of nano $\mathrm{CuZnO}_{2}$ compound.

and $\beta_{h k l}$ along $Y$-axis for the prepared $\mathrm{CuZnO}_{2}$ nanoparticles as shown in Figure 1(b). From the linear fit to the data, the crystalline size has been estimated from the $Y$-intercept as $115 \mathrm{~nm}$. This value exactly coincides with the value obtained from the Debye-Scherrer equation value. Further, strain $\varepsilon$, calculated from the slope of the fit, is 0.2948 .

4.2. EPR Spectral Analysis. EPR spectrum of $\mathrm{CuZnO}_{2}$ nanocompound recorded at room temperature is given in Figure 2. The spectrum indicates a strong resonance signal around $380 \mathrm{mT}$ in the high field region. This signal gives a " $g$ " value of 1.76 . Such a low value of " $g$ " may not be due to $\mathrm{Cu}(\mathrm{II})$. Generally, if $\mathrm{Cu}$ (II) is present in higher concentration in the compound it gives a single resonance signal with " $g$ " which is greater than 2.0, since the compound contains zinc, copper, and oxygen and this may be due to $\mathrm{Zn}(\mathrm{II})$ or $\mathrm{O}^{2-}$. But generally, a free radical of $\mathrm{O}^{2-}$ gives a signal around $\mathrm{DPPH}$. Therefore it is assigned to $\mathrm{Zn}$ (II) in the compound [5]. On the low field side two resonances are observed with $g$ values of 2.31 and 2.05. These are due to $\mathrm{Cu}(\mathrm{II})$ which is in tetragonal distortion. The copper complex exhibits $g_{\text {II }}$ at 2.31 and $g_{\perp}$ at 2.05 and $A_{\mathrm{II}}$ is $13.3 \mathrm{mT}$. These values indicate that the ground state of $\mathrm{Cu}(\mathrm{II})$ is $\mathrm{d}_{x}{ }^{2}-\mathrm{d}_{y}{ }^{2}$. Using the above values the covalency parameter $\alpha^{2}$ is calculated with the equation [6]:

$$
\alpha^{2}=-\left(\frac{A_{\mathrm{II}}}{0.036}\right)+\left(g_{\mathrm{II}}-g_{e}\right)+\frac{3}{7}\left(g_{\perp}-g_{e}\right)+0.04
$$

If $\alpha^{2}$ is 0.5 , it indicates a pure covalent bonding and if $\alpha^{2}$ is 1.0 , it indicates a complete ionic bonding between metal ion and the ligands. In the present case, the observed value of $\alpha^{2}$ is 0.74 which is less than unity and indicates that the compound has some covalent character existing in the ligand environment. Hence the compound is electrically less conductive.

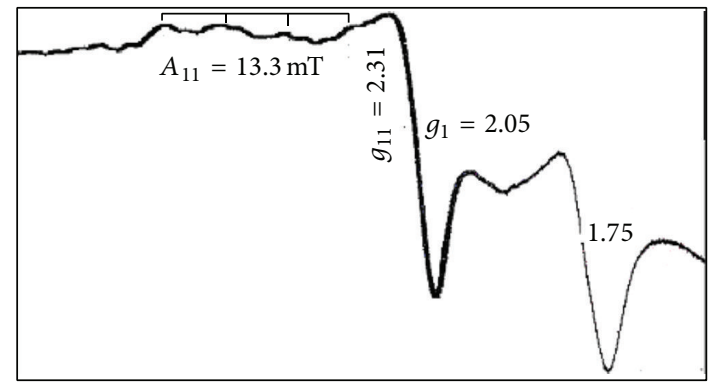

FIgURE 2: EPR spectrum of nano $\mathrm{CuZnO}_{2}$ compound recorded at $\mathrm{RT}(\nu=9.4 \mathrm{GHz})$.

4.3. Transmission Electron Microscope (TEM). TEM is employed to visualize the size and shape and to confirm the nanocrystalline nature of the synthesized copper doped zincoxide. Figure 3(a) shows the typical bright field TEM images of the synthesized $\mathrm{CuZnO}_{2}$ nanoparticles. It is observed from the image that the particles are clearly well separated and essentially no aggregation is found. Several uniform bright rings are also noticed. These are in spherical shape with almost the same dimension. This property suggests that the nanocrystals have preferential instead of random orientations. Further TEM images are showing that the metal ion may be in hexagonal structure with oxygen ligands. The particle size is about $100 \mathrm{~nm}$. This value of the crystallite size is coinciding with XRD value.

Figure 3(b) shows the selected-area electron diffraction (SAED) pattern of the nano $\mathrm{CuZnO}_{2}$ particles. The electron diffraction (ED) pattern consists of concentric rings with spots over the rings. This feature indicates that the samples are crystalline in nature. The rings in ED confirm the wide size distribution of $\mathrm{CuZnO}_{2}$ nanoparticles. 

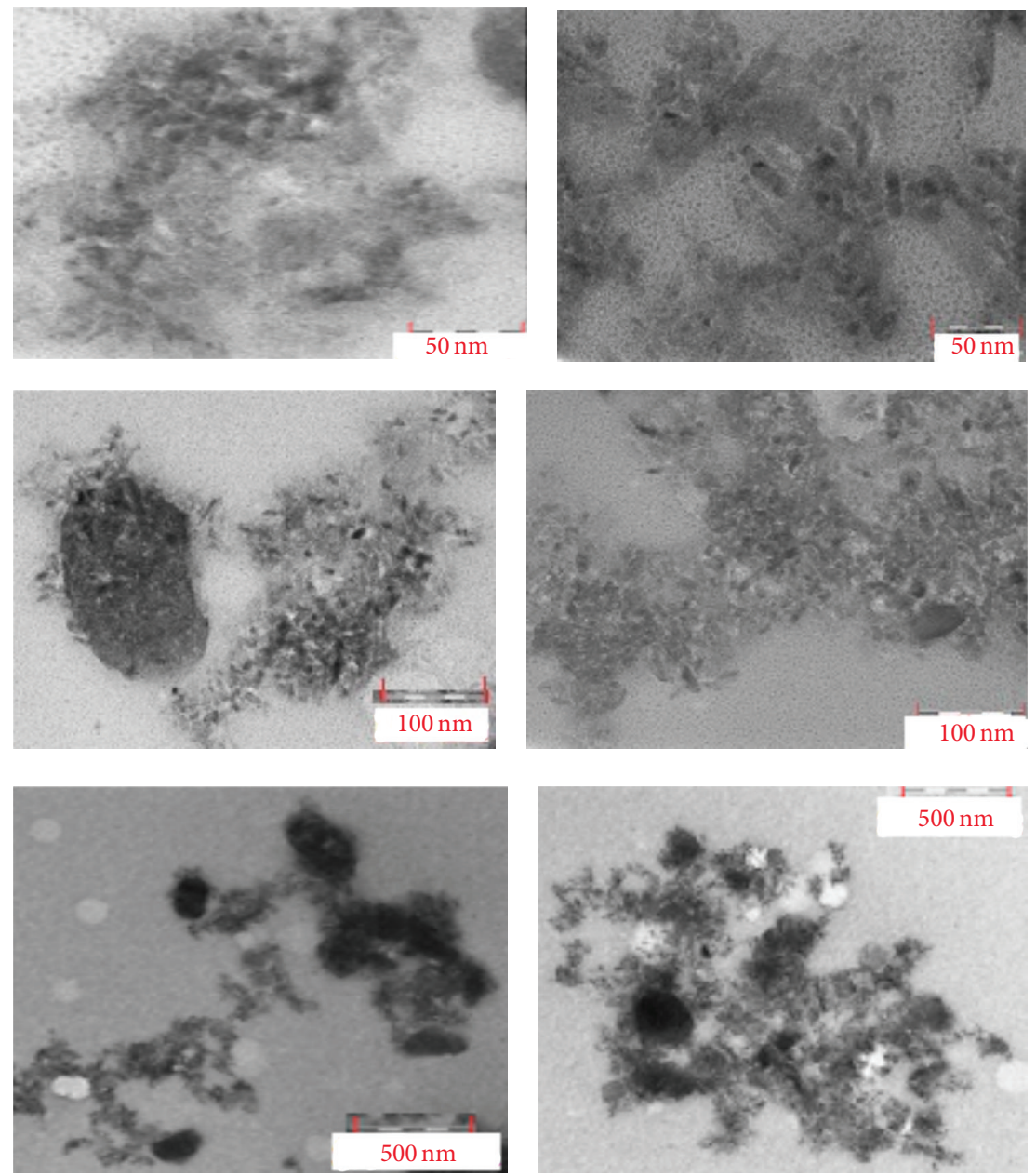

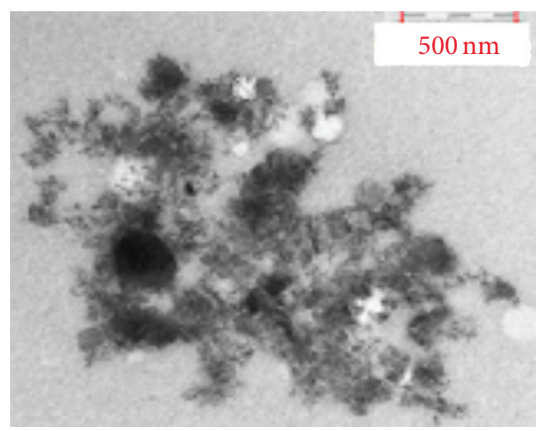

(a)

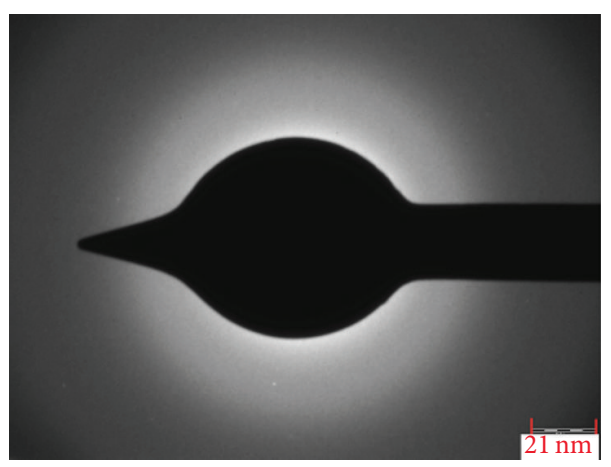

(b)

FIgURE 3: TEM micrographs of nano $\mathrm{CuZnO}_{2}$ compound.

4.4. Optical Absorption Spectral Analysis. The total optical absorption spectrum of nano $\mathrm{CuZnO}_{2}$ compound that is recorded in the mull form at room temperature (RT) from 200 to $2500 \mathrm{~nm}$ is shown in Figure 4(a). The band component analysis is conveniently divided into several ranges, as shown in Figures 4(b)-4(f).

4.4.1. 200-500 nm Spectral Region. Figure 4(b) shows optical absorption spectrum of the material at room temperature in the range of $200-500 \mathrm{~nm}$. The spectrum shows three sharp peaks. They are at $48780(205 \mathrm{~nm}), 44440(225 \mathrm{~nm})$, $37735(260 \mathrm{~nm})$, and $35715(280 \mathrm{~nm}) \mathrm{cm}^{-1}$. The high intensity band at $48780(205 \mathrm{~nm}) \mathrm{cm}^{-1}$ and low intensity band at $44440(225 \mathrm{~nm}) \mathrm{cm}^{-1}$ are due to metal-ligand charge transfer transitions. The moderate intensity band with components at $37735(260 \mathrm{~nm})$ and $35715(280 \mathrm{~nm}) \mathrm{cm}^{-1}$ gives energies of 3.4 and $3.3 \mathrm{eV}$. This may be due to the presence of copper in the zinc-oxide. Thus the optical absorption spectral measurements indicate red shift in the absorption band due to the presence of copper oxide.
4.4.2. 500-1300 nm Spectral Region. Figure 4(c) represents optical absorption spectrum of the compound in the range of $500-1300 \mathrm{~nm}$. The optical absorption spectrum is analyzed as follows.

The broad band observed at $9130 \mathrm{~cm}^{-1}(1095 \mathrm{~nm})$, intense band at $10750 \mathrm{~cm}^{-1}(930 \mathrm{~nm})$, and a profile of bands with high intensity at $14390 \mathrm{~cm}^{-1}(690 \mathrm{~nm})$ with components on either side at $12345(810 \mathrm{~nm}), 13160(755 \mathrm{~nm})$, and 15870 $(630 \mathrm{~nm}) \mathrm{cm}^{-1}$ are due to $\mathrm{Cu}^{2+}$ in the material. The observed three bands are assigned to $\mathrm{Cu}^{2+}$ in tetragonal symmetry. Accordingly three bands observed at $9130(1095 \mathrm{~nm})$ and $10750(930 \mathrm{~nm}) \mathrm{cm}^{-1}$ and a heap of bands with maximum intensity at $14390(690 \mathrm{~nm}) \mathrm{cm}^{-1}$ are assigned to ${ }^{2} \mathrm{~B}_{1} \rightarrow$ ${ }^{2} \mathrm{~A}_{1},{ }^{2} \mathrm{~B}_{1} \rightarrow{ }^{2} \mathrm{~B}_{2}$, and ${ }^{2} \mathrm{~B}_{1} \rightarrow{ }^{2} \mathrm{E}$ transitions, respectively. The crystal field $\left(D_{q}\right)$ and tetragonal $\left(D_{s}\right.$ and $\left.D_{t}\right)$ parameters are evaluated using the expressions given in theory [3]. The parameters evaluated are $D_{q}=1075 \mathrm{~cm}^{-1}, D_{s}=1824 \mathrm{~cm}^{-1}$, and $D_{t}=366 \mathrm{~cm}^{-1}$. The same sign for $D_{s}$ and $D_{t}$ indicated axial elongation of the tetragonal field [7]. This also confirms that the ground state is $\mathrm{d}_{x}{ }^{2}-\mathrm{d}_{y}{ }^{2}$ [8]. 


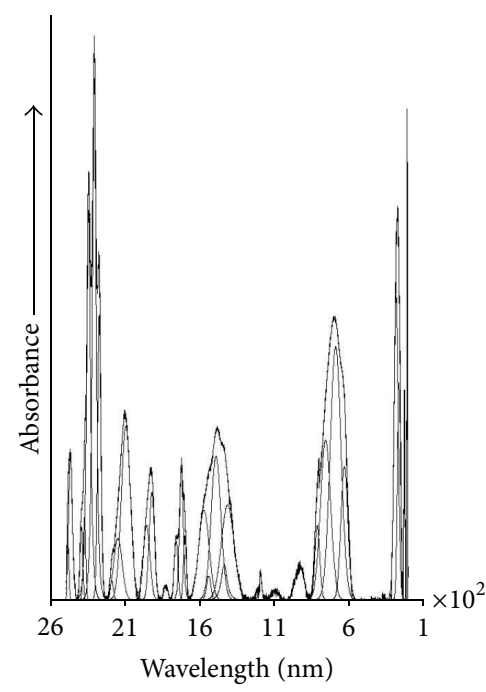

(a)

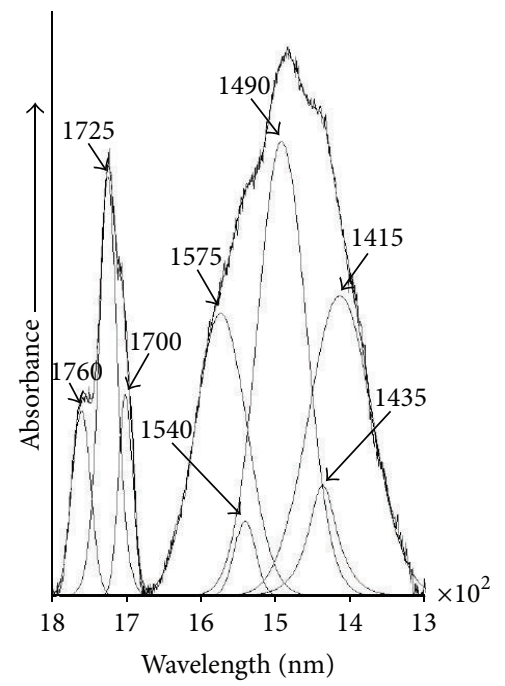

(d)

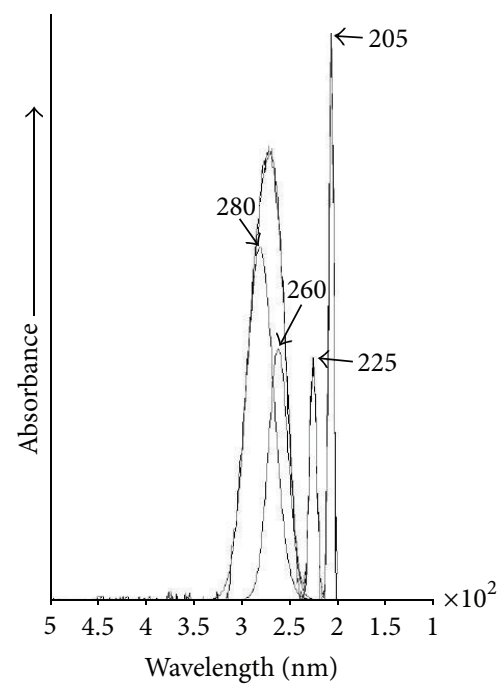

(b)

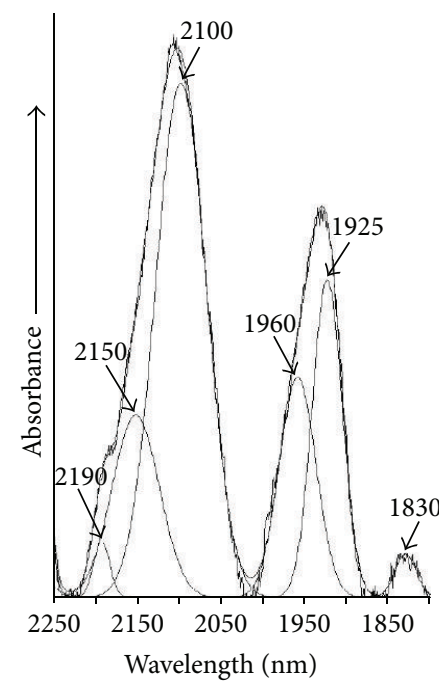

(e)

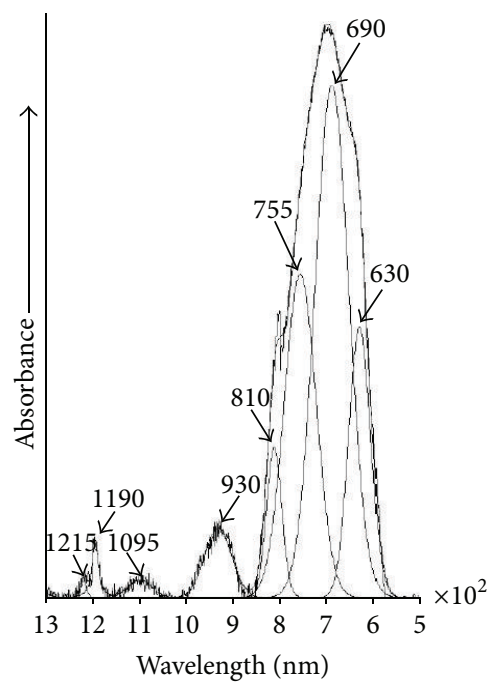

(c)

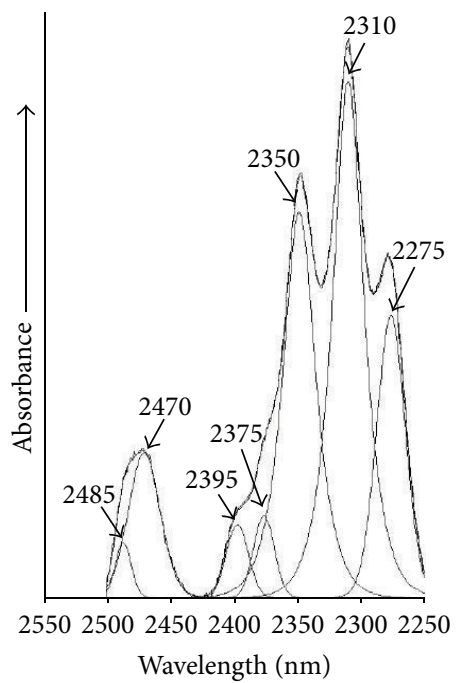

(f)

FIGURE 4: (a) Total optical absorption spectrum recorded at RT in the range of 200-2500 nm. (b) Optical absorption spectrum of nano $\mathrm{CuZnO}_{2}$ compound at RT in the range of $200-500 \mathrm{~nm}$. (c) Optical absorption spectrum of nano $\mathrm{CuZnO}_{2}$ compound at $\mathrm{RT}$ in the range of 500-1300 nm. (d) NIR spectrum of nano $\mathrm{CuZnO}_{2}$ compound at RT in the range of 1300-1800 nm. (e) $\mathrm{NIR}$ spectrum of nano CuZnO 2 compound at RT in the range of $1800-2250 \mathrm{~nm}$. (f) NIR spectrum of nano $\mathrm{CuZnO}_{2}$ compound at RT in the range of 2250-2500 $\mathrm{nm}$.

Using the EPR and optical absorption results, the spinorbit coupling constant $\lambda$ is calculated with the formulae [8]:

$$
\begin{gathered}
g_{\text {aver }}=\frac{1}{3}\left[g_{\mathrm{II}}+2 g_{\perp}\right] \\
g_{\text {aver }}=2\left[1-\frac{2 \lambda}{10 D_{q}}\right] .
\end{gathered}
$$

The $\lambda$ obtained is $366 \mathrm{~cm}^{-1}$ (for free $\mathrm{Cu}(\mathrm{II})$ is $-832 \mathrm{~cm}^{-1}$ ) which indicates some part of covalent bond existing between metal and ligand.

4.5. NIR Studies. $\mathrm{H}_{2} \mathrm{O}$ has $\mathrm{C}_{2 V}$ symmetry. It gives three fundamental modes. They are $v_{1}, v_{2}$, and $v_{3} . v_{1}$ represents symmetric $\mathrm{OH}$ stretch, $v_{2}$ the asymmetric $\mathrm{OH}$ stretch, and $v_{3}$ the $\mathrm{H}-\mathrm{O}-\mathrm{H}$ bend, respectively. In vapour phase $v_{1}$ occurs at $3652, v_{2}$ at 1595 , and $v_{3}$ at $3756 \mathrm{~cm}^{-1}$, respectively [9]. In liquid phase they are shifted to 3219,1645 , and $3445 \mathrm{~cm}^{-1}$, whereas in solid phase they are shifted to 3200,1640 , and $3400 \mathrm{~cm}^{-1}$. The shifts of $v_{1}$ and $v_{3}$ towards the lower frequency side and $v_{2}$ towards the higher frequency side are characteristic of hydrogen bonding [10].

The results of the band component analysis of the NIR spectra recorded at room temperature of the compound are split into different regions. From the figures, it is evident that several sharp absorptions with maximum intensity are observed in the sample. These are divided as 1300 to 
$1800 \mathrm{~nm}$ [shown in Figure 4(d)], 1800 to $2250 \mathrm{~nm}$ [shown in Figure 4(e)], and 2250 to $2500 \mathrm{~nm}$ [shown in Figure 4(f)].

The very sharp bands observed [Figure 4(c)] at 8230 $(1215 \mathrm{~nm})$ and $8400(1190 \mathrm{~nm}) \mathrm{cm}^{-1}$ are assigned to the combination of $\nu_{1}+v_{2}+v_{3}\left(3200+1640+3400=8240 \mathrm{~cm}^{-1}\right)$ of water fundamentals. This may be occurred as contaminated water while synthesizing the compound.

4.5.1. The 1300 to $1800 \mathrm{~nm}$ Spectral Region. NIR spectrum of nanomaterial recorded from 1300 to $1800 \mathrm{~nm}$ is shown in Figure $4(\mathrm{~d})$. Figure shows two sets of profile bands around $6710 \mathrm{~cm}^{-1}(1490 \mathrm{~nm})$ with components and with the highest intensity in the entire region of the spectrum and another group of bands at $5800 \mathrm{~cm}^{-1}(1490 \mathrm{~nm})$ with components on either side. In general whenever water is present in compound two characteristic bands appear around $7000 \mathrm{~cm}^{-1}(1430 \mathrm{~nm})$ due to $2 v_{3}$ and $5200 \mathrm{~cm}^{-1}(1925 \mathrm{~nm})$ due to $\left(v_{2}+v_{3}\right)$. When the bands are broad, it indicates that water molecules are relatively disordered and when the bands are sharp it indicates that water molecules are located in well-defined ordered sites [10]. These water molecules may be due to oxygen bonded or due to interstitial presence of water in the compound. These will not contribute to the formation of the compound.

Figure 4(d) shows a sharp band at $6710 \mathrm{~cm}^{-1}(1490 \mathrm{~nm})$ and is resolved into one sharp peak at $6710(1410 \mathrm{~nm})$ and four weak bands at $7170(1395 \mathrm{~nm}), 6970$ (1435 nm), 6495 $(1540 \mathrm{~nm})$, and $6360 \mathrm{~cm}^{-1}(1575 \mathrm{~nm})$. These are shifted to lower wave numbers and appear with distorted modes in the compound. It may also be explained that the possible substitution of $\mathrm{Cu}$ for $\mathrm{Zn}$ is responsible for the complexity of bands in the spectra. Bands from $7170(1395 \mathrm{~nm})$ to $6500 \mathrm{~cm}^{-1}$ $(1540 \mathrm{~nm})$ correspond to the overtones of $\mathrm{OH}$ stretching vibrational mode. Bands appearing as shoulders to the sharp peak at $6710 \mathrm{~cm}^{-1}(1490 \mathrm{~nm})$ may be attributed to the combination of $\mathrm{OH}$ stretching fundamental and metal-OH deformation modes. The sharp band observed at $5800 \mathrm{~cm}^{-1}$ $(1725 \mathrm{~nm})$ with components on either side is identified as $v_{3}$ of $\mathrm{H}_{2} \mathrm{O}$ molecule.

4.5.2. 1800 to $2250 \mathrm{~nm}$ Spectral Region. Figure 4(e) shows two sets of sharp bands one centered at $5195 \mathrm{~cm}^{-1}(1925 \mathrm{~nm})$ and another at $4760 \mathrm{~cm}^{-1}(2100 \mathrm{~nm})$. Each band is resolved into two or three components. The two prominent features involve the fundamental stretching combined with the fundamental $\mathrm{Cu}-\mathrm{O}-\mathrm{H}$ bend to give the band at $4760 \mathrm{~cm}^{-1}(2100 \mathrm{~nm})$ with the first overtone of the band at $5800 \mathrm{~cm}^{-1}(1725 \mathrm{~nm})$ [11]. One set of sharp bands centered around $5195 \mathrm{~cm}^{-1}(1925 \mathrm{~nm})$ is the combination of the frequency lattice modes with the combination bend at $4760 \mathrm{~cm}^{-1}(2100 \mathrm{~nm})$ [12]

4.5.3. 2250 to $2500 \mathrm{~nm}$ Spectral Region. Figure 4(f) shows a very sharp group of sharp bands with components and a moderate intensity band at $4050 \mathrm{~cm}^{-1}(2470 \mathrm{~nm})$. The most pronounced band centered at $4330 \mathrm{~cm}^{-1}(2310 \mathrm{~nm})$ in the nanocompound with split component almost equal in width on either side at $4395(2275 \mathrm{~nm})$ and $4255 \mathrm{~cm}^{-1}(2350 \mathrm{~nm})$ is due to the fundamental bending mode combined with the lowest frequency of $\mathrm{OH}$ stretching fundamental.

The bands in between 4500 and $4300 \mathrm{~cm}^{-1}$ (2220$2325 \mathrm{~nm}$ ) appear due to the combination of $\mathrm{OH}$ stretching and $\mathrm{M}-\mathrm{OH}$ bending modes and the bands in the range of $4300-4200 \mathrm{~cm}^{-1}(2325-2380 \mathrm{~nm})$ are attributed to $\mathrm{M}-\mathrm{OH}$ vibrations [13]. These bands are assigned due to true $\mathrm{OH}$ vibrations. The low wave number bands near $4050 \mathrm{~cm}^{-1}$ $(2470 \mathrm{~nm})$ may be attributed to metal-OH units.

\section{Conclusions}

(1) $\mathrm{CuO}$ and $\mathrm{ZnO}$ are given equal proportions and $\mathrm{CuZnO}_{2}$ nanocompound is synthesized by thermal decomposition method.

(2) $\mathrm{XRD}$ results indicate that $\mathrm{CuZnO}_{2}$ is in tetragonal symmetry with cell constants $a=3.1 \AA$ and $c=$ $3.4786 \AA$. Further the crystallite size calculated for the prominent peak as 115 agrees with the TEM results.

(3) EPR results suggest that the nano $\mathrm{CuZnO}_{2}$ compound $\mathrm{Cu}(\mathrm{II})$ ion has undergone Jahn-Teller distortion and is in the tetragonal elongated symmetrical environment which is further supporting the XRD results. Using EPR covalency character has been (calculated as 0.74) enhanced between metal and ligand in the compound. Hence the compound is electrically less conductive.

(4) TEM results clearly indicate that the particles are spherical in shape with almost the same dimension and they are clearly well separated. Hence no aggregation is found. Further TEM images show that the metal ion may be in tetragonal structure with oxygen ligands. The particle size is about $100 \mathrm{~nm}$. This value of the crystallite size is coinciding with XRD value. The selected-area electron diffraction (SAED) pattern of the nano $\mathrm{CuZnO}_{2}$ compound suggest that wide size distribution of nanoparticles is present in the compound.

(5) Optical absorption spectrum is due to $\mathrm{Cu}$ (II) and is placed in distorted octahedral environment. The crystal field parameters calculated are indicating that $\mathrm{Cu}$ (II) is in elongated tetragonal octahedral geometry. Using EPR and optical absorption results, the spinorbit coupling constant $\lambda$ is calculated as $366 \mathrm{~cm}^{-1}$ which indicates some covalent bond existing between metal and ligand.

(6) NIR results are due to water fundamentals and hydroxyls which indicate that the oxygens are not free but are bound to the metal ion as ligand atoms. During the synthesis of nano $\mathrm{CuZnO}_{2}$ some of the water molecules may be bound and it may be reflected in the NIR spectrum.

\section{Conflict of Interests}

The authors declare that there is no conflict of interests regarding the publication of this paper. 


\section{Acknowledgments}

The author S. Lakshmi Reddy is thankful to UGC, New Delhi, for financial assistance (Major Research Project no. 38-188/2009). Thanks are also due to the Head, SAIF, IIT, Chennai and Mumbai, for providing optical absorption spectra and TEM recordings.

\section{References}

[1] R. Chauhan, A. Kumar, and R. P. Chaudhary, "Synthesis and characterization of copper doped $\mathrm{ZnO}$ nanoparticles," Journal of Chemical and Pharmaceutical Research, vol. 2, no. 4, pp. 178$183,2010$.

[2] G. Korotcenkov, "Metal oxides for solid-state gas sensors: what determines our choice?" Materials Science and Engineering: B, vol. 139, no. 1, pp. 1-23, 2007.

[3] M. A. Hitachmann and T. D. Waite, "Electronic spectrum of the hexaaquocopper(2+) ion," Inorganic Chemistry, vol. 15, no. 9, pp. 2150-2154, 1976.

[4] C. Suryanarayana and M. Grant Norton, X-Ray Diffraction: A Practical Approach, Plenum Publishing Corporation, New York, NY, USA, 1998.

[5] S. Y. Wu, L. H. Wei, Z. H. Zhang, X. F. Wang, and Y. X. Hu, "Studies of the spin Hamiltonian parameters and local structure for $\mathrm{ZnO}: \mathrm{Cu}^{2+}$," Spectrochimica Acta A, vol. 71, no. 4, pp. 13071310, 2008.

[6] D. Kivelson and R. Neiman, "ESR studies on the bonding in copper complexes," Journal of Chemical Physics, vol. 35, no. 1, pp. 149-155, 1961.

[7] J. Fergusion, J. E. Word, and H. J. Guggenhim, "Electronic absorption spectra of tetragonal and pseudotetragonal cobalt(II). I. Dipotassium tetrafluorocobaltate, dirubidium tetrafluorocobaltate, dipotassium magnesium tetrafluorocobaltate, and dirubidium magnesium tetrafluorocobaltate," Inorganic Chemistry, vol. 14, no. 1, pp. 177-183, 1975.

[8] B. J. Halthaway and D. E. Billing, "The electronic properties and stereochemistry of mono-nuclear complexes of the copper(II) ion," Coordination Chemistry Reviews, vol. 5, no. 2, pp. 143-207, 1970.

[9] G. Herzberg, Molecular Spectra and Molecular Structure, vol. 2, Van Nostrand, New York, NY, USA, 1962.

[10] G. R. Hunt and J. W. Salisbury, "Visible and near-infrared spectra of minerals and rocks. I. Silicate minerals," Modern Geology, vol. 1, pp. 283-300, 1970.

[11] P. Sreeramulu, K. M. Reddy, A. Sundar Jacob, and B. J. Reddy, "UV-VIS, NIR, IR, and EPR spectra of connellite," Journal of Crystallographic and Spectroscopic Research, vol. 20, no. 1, pp. 93-96, 1990.

[12] G. R. Hunt, J. W. Salisbury, and C. J. Lenhoff, "Visible and near infrared spectra of minerals and rocks III: oxides and hydroxides," Modern Geology, vol. 2, pp. 195-205, 1971.

[13] R. N. Clarck, T. King, M. Kleflwa, G. A. Swayze, and N. J. Vergo, "High spectral resolution reflectance spectroscopy of minerals," Journal of Geophysical Research, vol. 95, no. 8, pp. 12653-12680, 1990. 

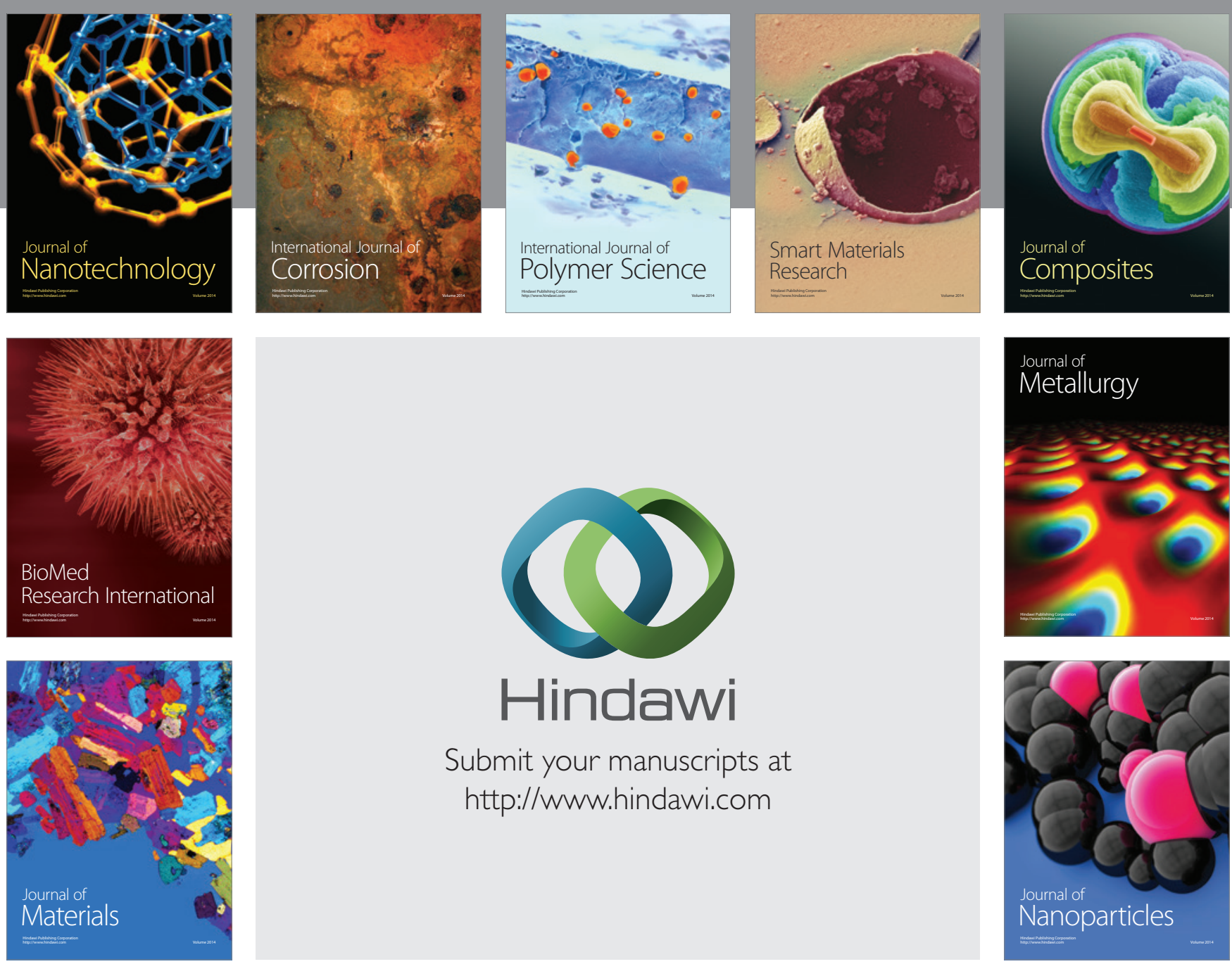

Submit your manuscripts at http://www.hindawi.com
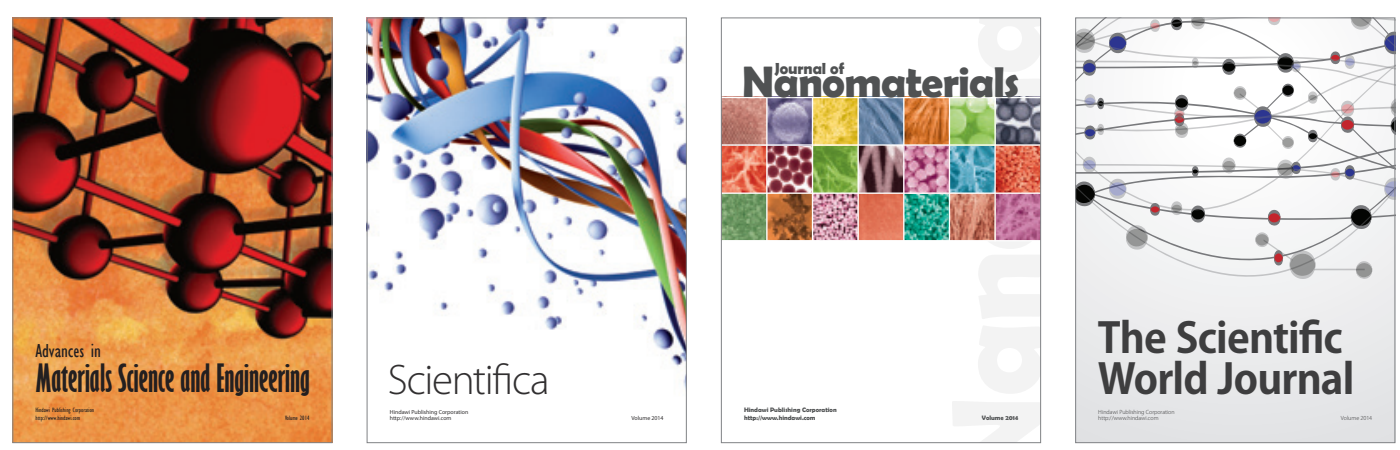

\section{The Scientific World Journal}
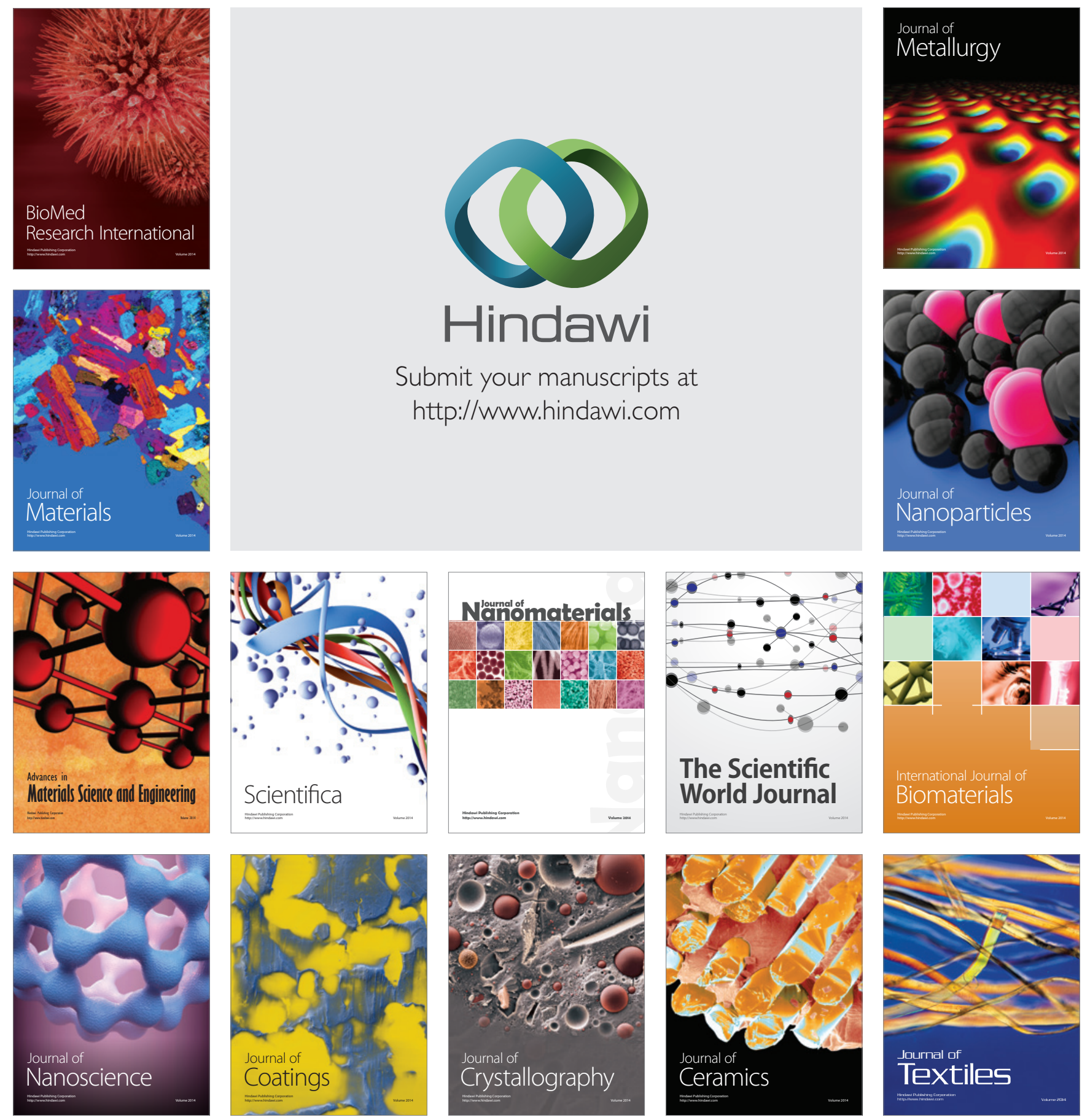